\title{
ANÁLISE HISTOLÓGICA DA BIOCOMPATIBILIDADE DE ADESIVOS \\ DENTINÁRIOS
}

\section{HISTOLOGICAL ANALYSIS OF THE DENTINAL ADESIVES}

\section{COMPATIBILITY}

\begin{abstract}
Fabrício José Araújo
Acadêmico do curso de graduação em odontologia da Universidade Vale do Rio Verde de Três Corações - UninCor e-mail: marcos.ribeiro.moise@terra.com.br

Sérgio José Costa Barbosa Mestrando em Clínica Odontológica da Universidade Vale do Rio Verde de Três Corações - UninCor e-mail: sergio-barbosa@bol.com.br

Marcos Ribeiro Moysés PhD, Professor do curso de odontologia da Universidade Vale do Rio Verde de Três Corações - UninCor e-mail: marcos.ribeiro.moise@terra.com.br

Alessandro Antônio Costa Pereira $\mathrm{PhD}$, Professor do curso de odontologia da Universidade Federal de Alfenas - Unifal e-mail: aacpereira@globo.com

José Carlos Rabelo Ribeiro PhD, Professor do curso de odontologia da Universidade Vale do Rio Verde de Três Corações - UninCor e-mail: professorcae@uol.com.br

João Gustavo Rabelo Ribeiro PhD, Professor do curso de odontologia da Universidade Vale do Rio Verde de Três Corações - UninCor e-mail: jgurr@hotmail.com

Alexandre Tourino Mendonça $\mathrm{PhD}$, Professor da Universidade Vale do Rio Verde de Três Corações - UninCor e-mail: alexandretourino@gmail.com
\end{abstract}

\begin{abstract}
RESUMO: O objetivo deste estudo foi avaliar a compatibilidade biológica de três sistemas adesivos, por meio de implantes no tecido conjuntivo subcutâneo de ratos. Dezoito ratos foram submetidos a implantes de esponjas saturadas com sistemas adesivos. Realizou-se biópsia excisional da área do implante após 7, 15 e 30 dias. Os resultados mostraram, nos três grupos experimentais no período de 7 dias, intenso infiltrado inflamatório mono e polimorfonuclear (PMNs) com numerosos vasos sangüíneos e alterações circulatórias, como vasodilatação e edema, enquanto no grupo controle esses fenômenos foram discretos. Aos 14 dias a intensidade do processo inflamatório diminuiu em relação ao período anterior e entre os grupos experimentais notou-se maior intensidade inflamatória nos grupos Clearfil SE e Single Bond. Aos 30 dias de período experimental o Single Bond mostrou intenso infiltrado inflamatório, inclusive com áreas contendo PMNs, o material Clearfil SE mostrou-se com discreta a moderada inflamação crônica, e algumas células gigantes, o material Prompt L-Pop apresentou-se semelhante ao grupo controle, com cavidade preenchida por tecido de granulação, fibrosamento periférico e células gigantes multinucleadas junto ao material implantado. Considerando a metodologia adotada e suas limitações, o estudo permite inferir que o material Prompt L-Pop apresentou aos 14 e 30 dias de implante em subcutâneo de ratos uma melhor biocompatibilidade, quando comparado aos materiais Clearfil SE e Single Bond.
\end{abstract}

Palavras-chave: Odontologia. Adesivos dentinários. Materiais biocompatíveis. Compatibilidade biológica. Implantes de Medicamento.

ABSTRACT: The aim of this study was to evaluate the biological compatibility of three adesive systems by means of implants in rat subcutaneous connective tissue. Eighteen rats were submitted to implants of sponges saturated with adesive systems. Excision biopsy was carried out in the implant area after 7, 15, and 30 days. After the seven-day 
period, the three experimental groups showed intense inflammatory mono- and polymorphonuclear (PMNs) infiltrate with several blood vessels and circulatory alterations as vasodilation and edema, while in the control group these phenomena were discrete. After 14 days, the intensity of the inflammatory process decreased and among the experimental groups Clearfil SE and Single Bond groups presented greater inflammatory intensity. After 30 days, Single Bond has shown intense inflammatory infiltrate including areas with PMNs; the material Clearfil SE has shown discrete to moderate chronic inflammation and some giant cells; the material Prompt L-Pop was similar to the control group with the cavity filled with granulation tissue, peripheric fibrosis and multinuclear giant cells next to the implanted material. Considering the adopted methodology and its limitations, this study allows to infer that after days 14 and 30 the material Prompt L-Pop presented better biocompatibility when compared to the materials Clearfil SE and Single Bond in the rat subcutaneous tissue.

Key words: Dentistry. Adhesive systems. Biocompatible materials. Biological compatibility Drug implants.

\section{INTRODUÇÃO}

O principal objetivo dos adesivos dentinários é o estabelecimento de uma forte união mecânica entre o material restaurador e a estrutura dental, sendo fundamental que uma maior área possível de dentina entre em contato com o adesivo. Entretanto, substâncias comumente presentes nos sistemas adesivos apresentam efeito citotóxico definido (Al-Dawood \& Wennberg, 1993; Santos \& Barbosa, 1998; Costa et., 1999; Kostoryz et al., 2003). Diferentes componentes de materiais resinosos podem ser liberados em fase aquosa (Geurtsen et al., 1999) assim, quando aplicado em uma superfície molhada, tal como a dentina, monômeros livres não polimerizados são liberados difundindo através dos túbulos dentinários até a polpa coronária (Costa et al., 2000). Alguns trabalhos têm demonstrado que os monômeros liberados causam danos químicos às culturas de células (Stanislawski et al., 2003; Lafeuvre et al., 2005) além disso, mostraram que componentes resinosos não polimerizados causam na polpa uma resposta inflamatória crônica visível e reabsorção dentinária interna (De Souza et al., 2002). Condicionamento ácido da dentina, particularmente na parede pulpar de cavidades profundas parece aumentar a permeabilidade da dentina (Costa et al., 2000). Nesta situação clínica, demonstrou-se que a aplicação de adesivo dentinário pode resultar na penetração de monômero residual nos túbulos dentinários (Hebling et al., 1999) devido a uma reversão no fluxo do fluido intratubular causado pela fotopolimerização (Hashimoto et al., 2004). Uma vez que estes monômeros residuais alcançam o tecido pulpar, uma reação de corpo estranho será iniciada. Foram encontrados ao longo dos 300 dias após a realização do procedimento restaurador macrófagos em torno de componentes da resinosos (Costa et al., 2000), provocando uma resposta inflamatória crônica persistente (Costa et al., 2000; De Souza et al., 2002; De Souza et al., 2003).

Comumente, os adesivos dentinários são escolhidos com base em pesquisas de ensaios mecânicos e infiltração marginal, para avaliação da sua retentividade ao substrato dentinário e efetividade em selar a interface 
dente-restauração. Porém, como a dentina é considerada um tecido vivo pela sua interrelação com a polpa, a biocompatibilidade dos adesivos dentinários se torna um item importante para a sua seleção. Neste sentido, o presente trabalho tem a finalidade de comparar a biocompatibilidade de adesivos dentinários, implantados no tecido conjuntivo subcutâneo de ratos, pela análise da reação inflamatória induzida por estes sistemas e assim, fornecer subsídios para a seleção mais adequada desse material pelo cirurgiãodentista.

\section{MATERIAL E MÉTODO}

Foram selecionados e padronizados quanto à saúde, idade e peso (200 a 300 gramas) 36 ratos machos (Rattus norvegicus, Holtzman) do Biotério da UNINCOR, após aprovação do Comitê de Ética em Pesquisa da
UninCor (CEP). Todos os procedimentos foram executados em um ambiente asséptico e todos os instrumentos cirúrgicos esterilizados em autoclave.

Os ratos foram distribuídos em 4 grupos de acordo com o adesivo (1. Clearfil SE Bond - Kuraray Company Ltd, Kurashiki, Japan; 2. Adper Prompt L-Pop - 3M ESPE St. Paul, Minnesota, USA; 3. Adper Single Bond - St. Paul, Minnesota, USA ) e água, utilizada como controle. Cada rato recebeu dois implantes de esponjas de polivinil (PVA) que continha a mesma substância; conseqüentemente cada grupo consistiu em 9 ratos com dois implantes, tendo por resultado 18 amostras por grupo. Três animais de cada grupo, foram sacrificados após 7, 15 e 30 dias e o tecido que continha as esponjas e a substância correspondente foram analisados em microscópio de luz (Quadro 1).

Quadro 1- Distribuição dos grupos de acordo com o tipo de adesivo dentinário e período do sacrifício dos ratos

\begin{tabular}{|l|c|c|c|c|c|c|c|c|}
\hline \multirow{2}{*}{ Período } & \multicolumn{2}{|c|}{ Clearfil SE Bond } & \multicolumn{2}{c|}{ Adper Prompt L-Pop } & Adper Single Bond & \multicolumn{2}{c|}{ Controle } \\
\cline { 2 - 9 } & Ratos & Amostras & Ratos & Amostras & Ratos & Amostras & Ratos & Amostras \\
\hline 7 dias & 3 & 6 & 3 & 6 & 3 & 6 & 3 & 6 \\
30 dias & 3 & 6 & 3 & 6 & 3 & 6 & 3 & 6 \\
Total & 3 & 6 & 3 & 6 & 3 & 6 & 3 & 6 \\
\hline
\end{tabular}

Todos os animais receberam anestesia intra-peritoneal (ketamina $50 \mathrm{mg} / \mathrm{kg}$; xilazina $10 \mathrm{mg} / \mathrm{kg}$ ). A tricotomia da região dorsal do animal foi realizada com a utilização de lâminas de barbear para eliminação dos pêlos $(4 \times 4 \mathrm{~cm})$. A anti-sepsia do campo operatório 
foi realizada com digluconato de clorexidina a 4\%. Na linha média, eqüidistante da inserção da cauda e da cabeça do animal, foram realizadas duas incisões de aproximadamente $8 \mathrm{~mm}$ de comprimento utilizando lâmina de bisturi $\mathrm{n}^{\circ} 15$ adaptada a um cabo de bisturi. Com o auxílio de uma tesoura de ponta romba, o tecido subcutâneo foi divulsionado lateralmente, formando duas lojas cirúrgicas, com aproximadamente $18 \mathrm{~mm}$ de profundidade cada uma. Os adesivos dentinários (Clearfil SE Bond, Prompt L-Pop e Single Bond) foram preparados de acordo com as recomendações do fabricante. Esponjas de polivinil (PVA) autoclavadas, de 6,0 $\mathrm{mm}$ de comprimento e 2,0 $\mathrm{mm}$ de diâmetro, foram saturadas com 2 gotas dos respectivos sistemas adesivos e implantadas nas lojas cirúrgicas. Em seguida, as esponjas foram fotopolimerizadas com um aparelho fotopolimerizador (Optilight 600 - Gnatus, Ribeirão Preto, SP, Brasil), seguindo o tempo recomendado pelo fabricante. A cada 5 fotopolimerizações $\quad$ o aparelho fotopolimerizador teve sua intensidade de luz medida através de um radiômetro. Durante todo experimento, ocorreu uma variação da intensidade de luz de 580 a $600 \mathrm{~mW} / \mathrm{cm}^{2}$. Esponjas saturadas com água destilada foram também implantadas, com a finalidade de formar o grupo controle.

As lojas cirúrgicas foram suturadas com fio de sutura 4.0 (Jonhson e Jonhson) e os animais receberam injeção de dipirona sódica $(0.3 \mathrm{~mL} / 100 \mathrm{~g})$. Os ratos foram mantidos em gaiolas e alimentados com ração balanceada e água. Após 7, 15 e 30 dias os ratos foram anestesiados para a realização da biópsia excisional da área do implante, abrangendo tecido normal circunjacente suficiente. Posteriormente os animais foram sacrificados pela técnica cervical do deslocamento

Após processamento histotécnico de rotina do laboratório de anatomopatologia da UNINCOR e inclusão das peças em parafina, foram obtidos cortes microscópicos seriados de 6 micrômetros de espessura, os quais foram corados com hematoxilina e eosina. No exame ao microscópio de luz, foi comparada a reação inflamatória induzida por cada um dos adesivos dentinários junto às esponjas. Analisando-se os fenômenos inflamatórios e de cura. Esses eventos microscópicos foram classificados como leve, moderado e severo. A biocompatibilidade do material foi determinada de acordo com as normas de avaliação descritas pela ISO 10993-3 (MEDICAL DEVICE \& DIAGNOSTIC INDUSTRY, 2004)

\section{RESULTADO}

Os resultados mostraram, nos três grupos experimentais no período de 7 dias, intenso infiltrado inflamatório mono e polimorfonuclear com numerosos vasos sangüíneos e alterações circulatórias, como vasodilatação e edema, enquanto no grupo 
controle esses fenômenos foram discretos. Aos 14 dias a intensidade do processo inflamatório diminuiu em relação ao período anterior e entre os grupos experimentais notou-se maior intensidade inflamatória nos grupos Clearfil SE Bond e Adper Single Bond. Aos 30 dias de período experimental o adesivo Adper Single Bond mostrou moderado infiltrado inflamatório, em relação aos demais materiais testados. O adesivo Clearfil SE Bond mostrou-se com discreta a moderada inflamação crônica e algumas células gigantes e o adesivo Adper Prompt LPop apresentou-se semelhante ao grupo controle, com cavidade preenchida por tecido de granulação, fibrosamento periférico e células gigantes multinucleadas junto ao material implantado.

\section{DISCUSSÃO}

O teste de biocompatibilidade em tecidos subcutâneos de ratos contribui para a avaliação de materiais que são utilizados em contato com a polpa dentária direta ou indiretamente, bem como de outros tecidos vascularizados (Estrela, 2001). Esse teste é utilizado na interpretação de reação inflamatória instalada frente ao material implantado que atua como um agressor. A reação inflamatória inicialmente é mais intensa devido às técnicas cirúrgicas e agressividade do material implantado, sendo muitas vezes indistinta entre os materiais experimentais, portanto o ideal é desconsiderar as primeiras horas de experimento. Aos 7 dias espera-se uma organização da reação inflamatória que deverá ser mais intensa em função de características inerentes ao agressor e não à cirurgia de implante. No presente trabalho revelou uma discreta inflamação para a esponja contendo água e uma inflamação de moderada a intensa para os materiais com componentes químicos. Aos 14 e 30 dias, períodos utilizados em nosso estudo e que podem variar entre os trabalhos com metodologia de implantes subcutâneos, espera-se uma diferença nos graus da reação inflamatória que poderá ser interpretada como maior ou menor biocompatibilidade entre os materiais. Geralmente nota-se pequena área com necrose, edema e vasos dilatados e em redor uma organização fibrosa do organismo, com inflamação crônica e redução do número de vasos sanguíneos. Podem ser observadas células gigantes multinucleadas sugerindo a formação de granulomas que se instalam devido à esponja utilizada com o material de teste. A presença de células e a organização de granulomas, e a menor intensidade dos fenômenos vasculares da inflamação condizem com uma maior bicompatibilidade do material testado (Estrela, 2001). Os adesivos Clearfil SE Bond e principalmente o Adper Prompt L-POP foram os que mais se aproximaram desta caracterização aos 30 dias de período experimental. A avaliação da Biocompatibilidade de adesivos dentinários 
por meio de implantes em tecido subcutâneo de rato é de grande valia pois, a resposta do tecido é similar àquela esperada quando o mesmo material é aplicado à polpa dental mecanicamente exposta nos dentes humanos. Esse procedimento evita a utilização seres humanos em pesquisas científicas (Estrela, 2001).

Vários trabalhos avaliaram a biocompatibilidade de materiais odontológicos (Al-Dawood \& Wennberg, 1993; Santos \& Barbosa, 1998; Kostoryz et al., 2003; Costa et al., 2000; De Souza et al., 2002; Gilpatrick et al., 1996; Costa et al., 2003; Mussel et al., 2003; Cox et al., 2003). Entretanto, existem divergências entre as metodologias, principalmente nos que utilizam, implantes de sistemas adesivos em tecido subcutâneo de ratos, tubos de polietileno com adesivos pré-polimerizados. Entretanto, clinicamente o adesivo é colocado na superfície dentinária ou na polpa dental, na forma líquida, sendo posteriormente fotopolimerizado. Nesse estudo foram utilizadas esponjas de polivinil (PVA) saturadas com os respectivos adesivos, e inseridas no tecido subcutâneo de ratos, sendo fotopolimerizadas posteriormente, na tentativa de simular os procedimentos clínicos reais. Costa et al. (1999), utilizaram esponjas de polivinil (PVA) saturadas com adesivos, mas não foram fotopolimerizadas quando implantadas nas lojas cirúrgicas, ficando o adesivo e seus monômeros em íntimo contato com o tecido conjuntivo subcutâneo dos ratos. Em conseqüência, foi verificado efeitos citotóxicos dos adesivos dentinários, bem como à reação inflamatória persistente desencadeada pelos componentes resinosos. Segundo os autores esses materiais não parecem adequados para serem aplicados diretamente sobre o tecido conjuntivo.

Além da reação causada pelos adesivos dentinários, a influência do ácido fosfórico no processo é muito importante, pois os ácidos, quando aplicados diretamente sobre a dentina, ampliam as embocaduras dos túbulos dentinários, facilitando a penetração bacteriana e a movimentação dos fluídos (Nakabayashi \& Pashley, 2000).

Cox et al. (2003), acreditam que as respostas inflamatórias pulpares são causadas exclusivamente pela microinfiltração bacteriana, através de falhas na interface dente/restauração, demonstrando forte relação entre a presença de bactérias e a resposta pulpar inflamatória. Esta idéia é apoiada por Akimoto et al. (1998), que concluíram em seu trabalho com macacos, que sistemas adesivos não são tóxicos quando aplicados direta ou indiretamente sobre a polpa. Entretanto, outros pesquisadores não concordam com essa teoria (Santos \& Barbosa, 1998; Costa et., 1999; Gilpatrick et al., 1996; Cortes et al., 2000; Ivanyi et al., 2000). Segundo Consolaro et al. (1997), a necrose celular pode ser determinada pela ação de agentes físicos tais como radiações e traumatismos, agentes 
químicos tais como álcalis e ácidos, e agentes biológicos tais como bactérias, vírus e fungos. Reforçando essa teoria, Santos e Barbosa (1998) afirmaram que a agressão pulpar é uma evidência histológica independente da presença ou não de bactérias e contato pulpar, e que os adesivos possuem potencial irritativo à polpa. Corroborando com esta afirmação, diversos pesquisadores (Kostoryz et al., 2003; Koliniotou-Koubia et al., 2001; Vajrabhaya et al., 2003; Nagem-Filho et al., 2003) demostraram a citotoxicidade dos componentes dos sistemas adesivos. Essa divergência de resultados observada na literatura, poderia ser explicada pelo fato dos materiais utilizados apresentarem diferentes composições, diversos mecanismos e procedimentos de aplicação, além de variações metodológicas (Al-Dawood \& Wennberg, 1993). Diante do exposto, ao selecionarmos um sistema adesivo devemos levar em consideração a sua bicompatibilidade.

\section{CONCLUSÃO}

Considerando-se a metodologia empregada pode-se inferir, entre os adesivos analisados, que Adper Prompt L-POP foi o de melhor biocompatibilidade.

\section{REFERÊNCIAS}

AL-DAWOOD A, WENNBERG A.

Biocompatibility of dentin bonding agents. Endod Dent Traumatol., v.9, p.1-7, 1993.
AKIMOTO N, MOMOI Y, KOHNO A, SUZUKI S, OTSUKI M, SUZUKI S.

Biocompatibility of Clearfil Liner Bond 2 and Clearfil AP-X system on nonexposed and exposed primate teeth. Quintessence Int., v.29, p.177-88, 1998.

CONSOLARO A. Ácidos e sistemas adesivos sobre a polpa dentária: Uma abordagem

crítica. RBO., v.54, p.198-203, 1997.

CORTES O, GARCIA C, BERNABE A. Pulpal evaluation of two adhesive systems in rat teeth. J Clin Pediatr Dent., v.25, p.73-7, 2000.

COSTA CA, TEIXEIRA HM, DO

NASCIMENTO AB, HEBLING J.

Biocompatibility of an adhesive system and 2-hydroxyethylmethacrylate. J Dent Child., v.66, p.337-42, 1999.

COSTA CA, HEBLING J, HANKS CT. Current status of pulp capping with dentin adhesive systems: a review. Dent Mater., v.16, p.188-97, 2000.

COSTA CA, OLIVEIRA MF, GIRO EM, HEBLING J. Biocompatibility of resin-based materials used as pulp-capping agents. Int Endod J., v.36, p.831-9, 2003.

COX CF, KIM KM, STEVENSON RG 3RD, HAFEZ AA. Histological evaluation of a selfpriming etchant adhesive system. Compend Contin Educ Dent., v.24, p.17-20, 2003.

DE SOUZA COSTA CA, DO NASCIMENTO AB, TEIXEIRA HM. Response of human pulps following acid conditioning and application of a bonding agent in deep cavities. Dent Mater., v.18, p.543-51, 2002.

DE SOUZA COSTA CA, GIRO EMA, NASCIMENTO ABL, TEIXEIRA HM, HEBLING J. Short-term evaluation of the pulpo-dentin complex response to a resinmodi.ed glass-ionomer cement and a bonding agent applied in deep cavities. Dent Mater., v.19, p.739-46, 2003. 
ESTRELA C. Metodol. Científica: ensino e pesquisa em odontologia. 1. ed. São Paulo: Artes Médicas, 2001:483.

GEURTSEN W, SPAHL W, MULLER K, LEYHAUSEN G. Aqueous extracts from dentin adhesives contain cytotoxic chemical. J Biomed Mater Res Appl Biomater., v.48, p.772-7, 1999.

GILPATRICK RO, JOHNSON W, MOORE D, TURNER J. Pulpal response to dentin etched with 10\% phosphoric acid. Am J Dent., v.9, p.125-9, 1996.

HASHIMOTO M, ITO S, TAY FR, SVIZERO NR, SANO H, KAGA M. Fluid movement across the resin-dentin interface during and after bonding. J Dent Res., v.83, p.843-8, 2004.

HEBLING J, GIRO EMA, DE SOUZA COSTA CA. Human pulp response after an adhesive system application in deep cavities. J Dent., v.27, p.557-64, 1999.

IVANYI I, BALOGH AE, ROSIVALL L, NYARASDY I. In vivo examination of the Scotchbond Multi-Purpose Dental Adhesive System in rat (vitalmicroscopic study). Oper Dent., v.25, p.418-23, 2000.

KOLINIOTOU-KOUBIA E, DIONYSOPOULOS P, KOULAOUZIDOU EA, KORTSARIS AH, PAPADOGIANNIS Y. In vitro cytotoxicity of six dentin bonding agents. J Oral Rehabil., v.28, p.971-5, 2001.

KOSTORYZ EL, EICK JD, GLAROS AG, JUDY BM, WELSHONS WV, BURMASTER S. Biocompatibility of hydroxylated metabolites of BISGMA and BFDGE. J Dent Res., v.82, p.367-71, 2003.
MEDICAL DEVICE \& DIAGNOSTIC INDUSTRY. 1999. Disponível em: <http://www.devicelink.com/mddi/archive/ 99/01/017.html>. Acesso em: 16 set. 2004.

MUSSEL RL, DE SA SILVA E, COSTA AM, MANDARIM-DE-LACERDA CA. Mast cells in tissue response to dentistry materials: an adhesive resin, a calcium hydroxide and a glass ionomer cement. J Cell Mol Med., v.7, p.171-8, 2003.

NAGEM-FILHO H, MONTEIRO CR, NAGEM HD, LAGE-MARQUES JL. Effect of dental adhesives on the exudative phase of the inflammatory process in subcutaneous tissue of rats. Pesqui Odontol Bras., v.17, p.109-12, 2003.

NAKABAYASHI N, PASHLEY D.H. Hibridização dos tecidos dentais duros. 1.ed Rio de Janeiro: Quintessence, 2000: 129.

SANTOS WAG, BARBOSA SV. Reação pulpar aos condicionadores ácidos. Rev. ABO Nac., v.6, p.142-6, 1998.

STANISLAWSKI L, LEFEUVRE M, BOURD K, SOHEILI-MAJD E, GOLDBERG M, PERIANIN A. TEGDMAinduced toxicity in human .fibroblasts is associated with early and drastic glutathione depletion with subsequent production of oxygen reactive specimens. J Biomed Mater Res A., v.66, p.476-82, 2003.

VAJRABHAYA LO, PASASUK A, HARNIRATTISAI C. Cytotoxicity evaluation of single component dentin bonding agents.

Oper Dent., v.28, p.440-4, 2003.

LAFEUVRE M, AMJAAD W, GOLDBERG M, STANISLAWSKI L. TEGDMA induces mitochondrial damage and oxidative stress in human gingival fibroblasts. Biomater., v.26, p.5130-7, 2005. 